\title{
Urdimento
}

\section{O SOLO DE DANÇA NO SÉCULO XX: ENTRE PROPOSTA IDEOLÓGICA E ESTRATÉGIA DE SOBREVIVÊNCIA ${ }^{1}$}

\author{
Eugenia Casini Ropa ${ }^{2}$ \\ Tradução de Adriana Aikawa da Silveira Andrades
}

\begin{abstract}
Resumo
O ensaio propõe uma interpretação poética e ideológica da dança solo, forma coreográfica típica da modernidade, seguindo suas mudanças desde $\mathrm{o}$ século $\mathrm{XX}$ aos nossos dias e pondo-a em constante relação com as ideias e expectativas da sociedade e da cultura em que nasce.
\end{abstract}

Palavras-chave: história, dança, Século XX, solo.

Nas primeiras décadas do século XX, na Europa assim como nos Estados Unidos, são postas simultaneamente em prática na política, na sociedade, na cultura e na arte estratégias de mudança ou de evolução reformistas ou revolucionárias, com fins materiais e ideais por vezes muito diferentes e até contrastantes entre si, mas todas voltadas a uma renovação da sociedade da época. Desse processo complexo e, às vezes, contraditório de pensamento e de práticas sócio-culturais, frequentemente estimulado ou mesmo distorcido por impulsos utópicos e por uma mitificação ambígua tanto do potencial regenerativo do indivíduo como da força evolutiva da comunidade, participam também as artes e os artistas.

Especialmente a dança, com sua revolução radical ético-estética, que ganha corpo nos mesmos anos entre Alemanha e Estados Unidos e que se propõe a abarcar o ser humano em sua totalidade psicofísica, mostra-se completamente envolvida na busca de estratégias de renovação. Por uma vez,
'Este texto é uma adaptação da apresentação no Congresso "La Danse en solo, une figure singulière de la modernité", organizado pelo Centro Nacional de Dança e pelo Teatro da Cidade de Paris nos dias 29 e 30 de setembro de 2001.

²Eugenia Casini Ropa é professora de História da Dança na Universidade de Bolonha, Itália, diretora do curso de graduação em Disciplinas do Espetáculo e da

Associazione Nazionale Danza Educazione Scuola (DES), que promove a dança em âmbito educativo.

Estudiosa de teatro $\mathrm{e}$ dança do século XX, entre suas publicações, lembramos especialmente os volumes: La danza e l'agitprop (1988) e Alle origini della danza moderna (1990). 


\section{Urdimento}

${ }^{3}$ Adriana Aikawa da Silveira Andrade é tradutora profissional e Mestre em Estudos da Tradução pela UFSC.

${ }^{4} \mathrm{Cf}$., em italiano, CASINI ROPA, 1990 e CARANDINI \& VACCARINO, 1997. põe-se inclusive na vanguarda, oferecendo-se como laboratório experimental de um corpo, um movimento, uma expressão, um modo de ser e comunicar novo para um homem, uma mulher e um mundo que querem se regenerar. $\mathrm{E}$, sobretudo nas primeiras décadas, a nova dança para o novo século é individual e individualista, realização solitária de personalidades singulares e únicas, que escolhem e elaboram novas modalidades expressivas e performáticas e se colocam como modelos exemplares não só no interior da própria disciplina artística, bem como na sociedade em transformação. ${ }^{4}$

Daquele momento em diante, a dança solo se torna e permanece uma forma característica e constante por todo o século - e ainda o é no início do século XXI - como uma necessidade do artista moderno seja de pesquisa introspectiva como de uma maneira pessoal de refletir o mundo. Todavia, sua contribuição à reflexão e à crítica social assume nuances diversas de acordo com os diferentes contextos históricos.

As características ideológicas e inclusive políticas da dança solo revelam-se sob vários aspectos. Às vezes existe, de fato, um valor ideológico totalmente consciente, que a dança se propõe a transmitir tanto através de sua forma quanto de seus conteúdos mais ou menos explícitos; mas há também um valor ideológico implícito, que a dança exprime por si mesma, pelo simples fato de existir assim como é no contex to da própria época, e até independentemente de uma consciência precisa.

Proponho-me neste ensaio a discutir rapidamente algumas das implicações ideológicas do solo de dança no século XX, a partir de três breves olhares exemplificativos lançados de pontos de vista diferentes. O primeiro olhar, mais panorâmico, identifica principalmente o fio condutor das suas tensões ideológicas projetuais no que concerne o social e, em particular, o âmbito da questão feminina; o segundo, por sua vez, considera uma influência maior do pensamento social e político em seus modos expressivos e trata da dialética entre indivíduo e comunidade; o terceiro, enfim, é uma rápida olhada às motivações entre o poético, o ideológico e o funcional - do autor-dançarino contemporâneo.

\section{Solo/mulher}

As criações das iniciadoras da história moderna da dança são solos por necessidade histórica e poética. Nascem de personalidades únicas de talento especial e criatividade quase profética - verdadeiros "sinais" estéticosociológicos de mudança - decididas a encarnar sua visão pessoal de mundo numa qualidade nova de seu corpo em movimento. Que essas iniciadoras sejam mulheres e, além disso, inicialmente americanas, não é nada casual e dá um significado ideológico especial ao seu trabalho.

O solo de dança no século XX... Eugenia Casini Ropa

Março $2009-\mathrm{N}^{0} 12$ 


\section{Urdimento}

As primeiras manifestações da nova dança, aquela que rompe com as regras tradicionais do balé acadêmico, proclamando a estética da "natureza" contra a do "artifício" e que apresenta a dançarina sozinha com seu corpo e suas emoções reveladas na cena, são uma provocação viva não somente à instituição coral, uniformizada e tecnicista do balé, mas à completa concepção da mulher e de seu papel na sociedade. Fruto de imaginações criadoras isoladas, resumem em si e repropõem com eficácia todas as aspirações do despertar feminino da América e da Europa na aurora do novo século. Nos solos de Isadora Duncan (mas também nos de Ruth St. Denis e de Loïe Fuller) ${ }^{5}$ se manifesta, de fato, uma concentração das aspirações e reivindicações da mulher da época, que está se emancipando e se prepara para assumir um papel propositivo na sociedade.

É verdade que nos teatros americanos ou europeus de vaudeville, as bailarinas já se exibiam sozinhas em seus repertórios de skirt dance $e^{6}$, mas tinham pouca reputação tanto artística quanto social e dependiam unicamente do humor dos empresários e do público, por serem atrações eróticas de série, semelhantes no aspecto e facilmente substituíveis. Embora buscassem uma emancipação no trabalho e no sucesso, e algumas delas possuíssem habilidades notáveis como dançarinas, não faziam mais do que reafirmar o sistema discriminatório ao qual pertenciam. Exibiam uma máscara do próprio corpo e representavam um status feminino e artístico subalterno com relação à classe e cultura, ligado a um gosto masculino retrógrado e sensual do espetáculo de dança, apreciado como puro entretenimento digestivo. ${ }^{7}$

As novas solistas destroem e viram essa visão do avesso: transformam a representação de um papel em expressão de uma pessoa; seus corpos não são uma máscara, pelo contrário, como se dirá na Alemanha, vestem a alma como uma luva. Uma completamente diferente da outra fisicamente e nas escolhas estéticas, apresentam-se como individualidades descômodas e inconformadas, não assimiláveis à rotina existente, à qual, de fato, se opõem. Filhas da americanização do pensamento delsartiano ${ }^{8}$, abraçam a crença na unidade indissolúvel entre corpo e espírito no ser humano e em sua expressão; apresentam-se como paladinas de um corpo feminino liberado pela reforma das roupas e pelas conquistas no âmbito da saúde; exaltam as peculiaridades expressivas e culturalmente maiêuticas da mulher; tornam-se criadoras de suas performances em primeira pessoa e empresárias de si mesmas; e, sobretudo, lutam para dar à sua dança o estatuto de Arte e de Cultura. Suas estratégias culturais e artísticas, que se traduzem em poéticas pessoais e em solos, são diferentes, mas alcançam com perspicácia elementos bem presentes no clima cultural do momento. Duncan escolhe a Grécia e a Natureza, modelos éticoestéticos então dominantes no pensamento evolucionista e nacionalista da classe culta ocidental, para suas danças "pagãs" e vitalísticas, que ostentam um corpo liberado; St. Denis inspira-se no Oriente e em seus mitos, que também
${ }^{5}$ As três dançarinas americanas, que tiveram uma enorme influência na Europa, são consideradas as "mães inspiradoras" da dança moderna. Da ampla, mas quase sempre celebrativa bibliografia específica, limito-me a citar os estudos que se enquadram melhor ao tema aqui tratado: DALY, 1995; KENDALL, 1979; LISTA, 1994.

${ }^{6} \mathrm{~A}$ skirt dance (dança da saia) era a forma de dança em voga nos espetáculos de variedades ingleses e americanos de final dos Oitocentos. Alegre e saltitante, unia passos da dança popular com movimentos do balé e temperava tudo mostrando pernas torneadas e ágeis, com um grande abano das saias amplas, sabiamente manejadas. Para redescobrir a skirt dance, vide SPERLING, 2000 p. 53-56.

${ }^{7} \mathrm{Cf}$., sobre a condição da bailarina de vaudeville, os primeiros capítulos em CHALFA RUYTER, 1979.

${ }^{8} \mathrm{~A}$ vasta difusão americana da teoria da expressão de François Delsarte, revista sob a 


\section{Urdimento}

(cont.) forma de "ginástica harmônica" e de normas gerais de comportamento, caracterizou a educação feminina que se estende às últimas décadas dos Oitocentos, dando origem inclusive a um amplo número de publicações.

${ }^{9}$ Sobre os valores sociais do corpo cênico da dançarina dos Oitocentos até hoje, vide: BANES, 1998.

${ }^{10}$ É de se notar como essas primeiras dançarinas ressaltam, inclusive com atributos privados de vida e comportamentos sociais anticonformistas (é 0 caso de Duncan e Fuller), ou seja, que se ostentam como exemplos (como acontece com St. Denis), a vontade de sair dos esquemas: atitudes pessoais que ressoam nas exibições públicas de seus solos, aumentando seu valor de proposta subversiva.

${ }^{11}$ Após a Primeira Guerra Mundial, a mulher consegue maior liberdade e reconhecimento social, mas a definição de seu papel, ainda incerto, se lança na conquista de espaços e prerrogativas ainda masculinas. Sobre a "masculinização" estratégica do pensamento exerciam naquele tempo um fascínio potente e misterioso na cultura ocidental, para compor suas danças exóticas, que subliman o erotismo da fêmea em cena na espiritualidade do rito; Fuller reelabora e amplia a popular skirt dance, usando tecnologias de iluminação sofisticadas inventadas por ela mesma, criando fantasmagóricas "serpentinas" que influenciam o simbolismo, o art nouveau, o futurismo e moldam a técnica, território masculino, à fantasia feminina. Todas, porém, ao traduzir motivações e influências profundas e pessoais em uma concepção e um uso novo do corpo, do movimento e da energia, acabam por revelar necessidades latentes ou evidentes da sociedade em que vivem ${ }^{9}$.

Suas exibições solo exaltam e impõem à atenção um novo modelo de mulher que não é de série, mas uma mulher-pessoa, uma individualidade livre no corpo e na mente, criadora da própria arte e profissional competente, que influencia a construção global de uma nova cultura. ${ }^{10}$

Uma observação à parte, mas não indiferente, é interessante: nesse processo individual de afirmação de uma arte e de uma imagem feminina culturalmente enobrecidas e projetadas para o futuro, a feminilidade é exaltada em seus dotes peculiares e "naturais" de sensibilidade e harmonia psicofísica recuperados, enquanto é atenuada e mitigada a sexualidade. Nos solos das primeiras artistas da nova dança o apelo sexual é conscientemente atenuado, mascarado por um uso diverso da energia, velado por uma pátina de distanciamento ético e esvaziado de sua carga erótica. Para afirmar a cultura nascente da "Nova Mulher" emancipada e da arte da dança que a representa, é preciso cortar os pontos em comum com a imagem sensual da mulher-bailarina, e a nova dançarina, embora encerre em si a essência de seu "gênero" renovado, perde parte de sua conotação sexual, em favor de uma conotação mais espiritual.

Esse fenômeno será ainda mais evidente, em seguida, nas grandes intérpretes dos anos vinte e trinta, como Mary Wigman ou Martha Graham e, de modo geral, em muitos solos femininos de dança do século XX, nos quais haverá um uso cada vez mais intenso da energia e, por vezes, com uma qualidade realmente andrógina da pessoa e do movimento.

Durante o século, os modelos femininos da sociedade que os solos das dançarinas criticam modificam-se notavelmente. Da proposta tardo-romântica, viva e utópica de Duncan, de uma mulher vista como símbolo de beleza corpórea e espiritual e única salvação do mundo contra a lógica masculina da tecnologia e da luta pelo poder, se passa logo aos solos mais inquietantes e problemáticos de Wigman e Graham. Em pleno modernismo, não mais presas aos mitos de originalidade natural ou de retorno ao passado, essas artistas frequentemente buscam nas elaborações e nos arquétipos do inconsciente contemporâneo uma 


\section{Urdimento}

identidade feminina adequada aos próprios tempos (além de profissionalmente e socialmente concorrente ao outro sexo). E para afirmá-la, lutam, incorporando energias masculinas e, às vezes e em parte, dessexualizando-se ${ }^{11}$. Seu modelo de mulher, exposto nas criações individuais dos anos vinte e trinta, supera o conceito universalista anterior de harmonia, graça e beleza, para adotar um corpo "generativo" mais tenso e atormentado (que pode chegar ao grotesco ${ }^{12}$ ) e que privilegia, através de manifestações simbólicas, a revelação da psique e das modernas problemáticas existenciais. ${ }^{13}$

Dos anos sessenta em diante, a pesquisa pós-moderna impõe um corpo (e uma qualidade de movimento) não mais idealizado, exemplar e simbólico, mas histórico, democrático e quotidiano, e nega o viés psicologista anterior ${ }^{14}$. A adoção de gestos e vestes quotidianos e casuais implica evidentemente na aceitação da realidade historicamente contingente do sujeito. A dança, todavia, normalmente desestruturada pela cisão, pelo acúmulo e pela repetição, manifesta uma ânsia de análise metalinguística que demonstra uma urgência análoga de desconstrução e atribuição de sentido à qualidade do próprio existir como indivíduos no presente. Por vezes, a crítica à condição da mulher se torna mais direta e explícita nos solos femininos. Com o florescer do feminismo contemporâneo, muitas dançarinas descobrem e revelam com lúcida ironia a alienação e as neuroses da mulher na sociedade de consumo. Lucinda Childs, Susanne Linke, Reinhild Hoffmann, por exemplo, lutam em cena contra objetosfetiche que as prendem ao papel de donas-de-casa e consumidoras e parecem inibir nelas qualquer uso não neurotizado do próprio $\operatorname{corpo~}^{15}$. A este modelo de feminilidade atormentada parece contrapor-se a proposta de um corpo/mente cada vez mais envolvido com a própria sexualidade, funcional e curioso em relação às próprias possibilidades dinâmicas, que são experimentadas quase cientificamente, sem inibições e sem utopias, lucidamente e sem se deixar levar pela emotividade nem pela busca de significados ulteriores ${ }^{16}$.

Em seguida, a difusão da autoconsciência de matriz feminista e a diminuição geral das tensões ideológicas contribuem, depois da despersonalização pós-moderna e da indiferença à expressividade emocional, para que os solos se tornem normalmente mais introvertidos e se refugiem no intimismo e no autobiografismo, frequentemente explorados pelo instrumento da improvisação dinâmica. É uma proposta à mulher para que ela redescubra sua história individual num reencontro com a pessoa entendida holisticamente, consciente de um corpo e uma mente interativos e confiante de produzir autonomamente uma "dramaturgia" do movimento falante e pessoal. Às vezes, aparece à espreita, por trás da autossuficiência e na solidão criativa, o abandono complacente de uma renúncia solipsística, de uma introversão afásica, que inibe a comunicação e recusa a intervenção crítica direta, sinal da vontade de fugir de uma realidade cada vez mais privada de valores propositivos. (cont.) coreográfico no início da carreira de Graham, vide FRANKO, 1995, p. 38-74.

${ }^{12} 0$ grotesco é especialmente característico das criações alemãs. Pense na dança da bruxa (Hexentanz)

ou nas outras figuras dramáticas de Wigman ou nas deformações satíricas de Valeska Gert. Cf. BURT, 1998; PETER, 1987.

${ }^{13 E ́}$ a afirmação "expressionista" das protagonistas da dança moderna: se Wigman dá corpo aos estados da alma, Graham madura encarna os arquétipos clássicos da psique feminina propostos pela psicanálise.

${ }^{14}$ Sobre as tendências pós-modernas da dança vide especialmente: BANES, 1983 e 1987.

${ }^{15} \mathrm{Em}$ Carnation (1964) Childs manipula obsessivamente bobes, esponjas e escorredor de

macarrão, terminando com um desabafo contra a sacola de compras; em Im Bade Wannen (1980) Linke limpa de modo maníaco uma banheira reluzente; em Solo mit Sofa (1980)

Hoffman luta com uma roupa-capa que a une indissoluvelmente ao sofá de casa. 


\section{Urdimento}

${ }^{16}$ A própria Childs, em seu período "analítico", ou Trisha Brown, com suas composições matemáticas, são exemplos gritantes. (Cf. BANES, 1987, nos capítulos dedicados a elas).

${ }^{17}$ As vicissitudes ideológicas e políticas da Alemanha entre República de Weimar e III Reich são emblemáticas nesse sentido (mas a questão urge igualmente, mesmo se em termos politicamente diferentes, na Rússia da nova era soviética e nos Estados Unidos dos anos trinta). Sobre a dialética singular entre indivíduo e comunidade no pensamento, na arte e na cultura do corpo da Alemanha das primeiras quatro décadas do século, vide, em especial, 0 estudo fundamental de BAXMANN, 2000. Para uma leitura da relação dança/ pensamento político nos Estados Unidos do século XX, é iluminador 0 já citado FRANKO, 1995.

${ }^{18} \mathrm{Em}$ italiano, vide JAQUES-DALCROZE, 1986.

\section{Solo/coro}

Ao longo dos primeiros quarenta anos do século XX, portanto, o solo se torna uma constante nas criações de dança. Aliás, são os próprios pressupostos teórico-filosóficos da dança moder na que impõem logicamente esse modelo. Se a nova dança funda-se no princípio de que qualquer homem ou mulher é potencialmente dançarino(a), e que cada dançarino(a) pode dar forma simbólica e/ou mimética à expressão completa de si pelo movimento e ritmo, segundo normas derivadas de princípios naturais, então é totalmente lógico - e necessário - que cada artista identifique e elabore suas próprias formas pessoais.

Essa visão profundamente individualista da dança e da arte em geral reflete um modelo de pensamento burguês tardo-romântico, já bem radicado na cultura de início de século e claramente alimentado pela evolução dos estudos sobre o psiquismo individual e a personalidade, pelas novas idéias científicas relativistas e por filosofias como a nietzschiana. Ele convive, porém, e entra em conflito ou em dialética ativa, com outras linhas ou variantes do pensamento cada vez mais difundidas, promovidas com semelhanças ambíguas, tanto à direita como à esquerda, pelos nacionalismos crescentes e totalitarismos nascentes, que tendem a privilegiar e propor modelos coletivos de sociedade e de cultura, nos quais os indivíduos e suas ideias fundam-se, "espontaneamente" uniformizadas, numa comunidade de intenções e ações. Nasce assim, no dizer e no fazer político e pedagógico, no social bem como na arte, uma dicotomia ideológica entre a exaltação do individualismo, como modelo de plena realização pessoal do homem e do artista, e a tensão, normalmente com uma força utópica imponente e impulsora, voltada para uma sociedade e um pensamento comunitários e unânimes ${ }^{17}$. Como conciliar estas duas visões contrastantes e harmonizar os indivíduos em um todo, sem perder a identidade e a riqueza propositiva dos sujeitos nem a coesão e a força da coletividade? Este conflito se reflete amplamente na dança, transformando-se frequentemente em uma dialética complexa entre individualidade e coralidade. Alguns mestres muito importantes - e nesse caso são inicialmente do sexo masculino - buscam, mais tradicionalmente, métodos comuns a incorporar ou, de modo mais inovador, motivações compartilhadas a serem externalizadas, para homogeneizar "coros dançantes" com bases novas. Émile Jaques-Dalcroze, por exemplo, através de seu método pedagógico de sensibilização ao ritmo musical, harmoniza os grupos, formando os indivíduos numa "euritmia" que olha nostálgica para o mito da Grécia clássica, mas que em suas formas conhecidas consegue fluir facilmente numa bem estruturada ginástica ritmada. ${ }^{18}$ Rudolf von Laban, por sua vez, cria coros de movimento dinamicamente coesos a partir da base "eucinética" da gestualidade do trabalho comum ou da expressão comum de 


\section{Urdimento}

estados interiores ${ }^{19}$. Sonha - conforme os mitos comunitários do momento com um "templo dançante", em que os movimentos expressivos e peculiares de cada um se reúnem numa base antropológica formada pela comunhão profunda de crenças, necessidades e modos de vida. Uma perspectiva artisticamente estimulante, mas politicamente ambígua e perigosa: o poder nazista logo perceberá sua incongruência em relação à própria estratégia massificante e a exilará junto com a "degenerada”, e expressiva demais, nova dança, voltandose decididamente às poderosas liturgias ginásticas e marciais.

A vontade de encontrar modos adequados ao novo controle espaçotemporal do corpo na era da mecanização leva a visões geométricas, matemáticas e arquitetônicas das formas corpóreas intrinsecamente despersonalizantes, funcionais e eficazes para os grandes números. Reavalia-se na arte o conceito grego de technè, que submete à técnica os materiais de criação. Estuda-se a marionete para roubar os automatismos de seu funcionamento; considera-se o organismo humano semelhante a uma máquina biológica a ser aperfeiçoada ${ }^{20}$. A organicidade pulsante de corpo e alma, conquistada por outros a muito custo, torna-se um perigo ou um obstáculo por suas respostas muito sujeitas à imprevisibilidade dos estados emocionais e dos impulsos expressivos individuais; melhor seria a eficiência programável de respostas gínico-musculares automatizadas.

Nesta perspectiva, que valor assume, de um ponto de vista ideológico, o solo de dança? De um lado continua a ser o lugar artístico da manifestação orgulhosa e irrenunciável da pessoa e da personalidade, em sua singularidade e variabilidade; o lugar solitário, mas autossuficiente da revelação do imaginário e do patrimônio de memórias e sentimentos individuais; o lugar do abandono e da gestão livre do corpo e do movimento. Como tal, parece definitivamente resistir e constituir uma crítica viva a uma ideologia social e política da coralidade induzida e da uniformização eficiente, que conduz inevitavelmente ao controle projetual do corpo e limita as escolhas tanto nas formas quanto nos significados. Porém, o corpo do indivíduo que dança, ao cumprir uma função não somente centrífuga mas também centrípeta em relação ao social, pode se tornar inclusive o lugar da síntese expressiva e comunicativa de pensamentos, sentimentos e características coletivas. Neste sentido, é interessante reler as perguntas retóricas, falsamente ingênuas, que Béla Balász, grande teórico do cinema das origens e militante do teatro revolucionário operário alemão, se fazia justamente em 1929 sobre a arte coletiva impulsionada pelo socialismo: o que é arte coletiva? Uma massa uniformizada que age como um só corpo ou um indivíduo sozinho que com criatividade revela no próprio corpo o espírito de uma massa com a qual se identifica? Faz-se desaparecer o homem no coro ou se faz aparecer o coro no homem? ${ }^{21}$

Março $2009-\mathrm{N}^{\circ} 12$

O solo de dança no século XX... Eugenia Casini Ropa
${ }^{19}$ Em italiano, LABAN, 1999; ed. orig. LABAN, 1950.
${ }^{21}$ Cf. CASINI ROPA, 1980, pp. 105-106.
${ }^{20}$ Os elementos de discussão e experimentação introduzidos pelo modernismo começam a ser adotados também no âmbito das artes do movimento: lembremos as tentativas futuristas ou as de Schlemmer na Bauhaus, bem como a experiência biomecânica de Meyerhold ou a construtivista de Foregger, na Rússia. Se a pesquisa destes artistas é poeticamente motivada, os sistemas de poder usam alguns de seus princípios em direção massificante. 


\section{Urdimento}

${ }^{22}$ Cf. DUNCAN, 1980.

${ }^{23}$ Cf. WIGMAN, 1963.

${ }^{24} \mathrm{Cf}$. Giannina Censi. Danzare il futurismo, organizado por VACARINO, 1998. Contém também manifesto La danza futurista (1917), de F.T. Marinetti, p. 98-99.
Já Duncan, mergulhada em sua mitologia pessoal, afirmava resumir em si o espírito do coro grego. Sentia-se intérprete de princípios, aspirações e sentimentos universais, filtrados pela sensibilidade e pelos meios pessoais. Experimentou inclusive as dificuldades da criação de um verdadeiro coro de individualidades dançantes através de suas escolas. Para criar uma verdadeira comunidade dançante, convenceu-se, com o tempo, de que não bastavam os exemplos a imitar ou as regras a seguir, era preciso fazê-la crescer unida no desejo de beleza e no direito à auto-expressão sobre bases sociais igualitárias. E lhe pareceu, por um instante, ter encontrado o contexto ideal na Rússia de Lênin ${ }^{22}$.

Também Graham e Wigman, assim como outras dançarinas de sua época, embora personalidades fora do comum, têm o forte sentimento de pertencimento a uma comunidade social e cultural, além do de classe: a própria geração e/ou nação. Captam seus temas e sentimentos e os levam a extremo nos solos, ainda que por meio de particularidades e do estilo do próprio corpo e da própria estética: compartilham motivos gerais e os destilam em essência universal ou de época. A dor de Lamentation (1930), incorporado no longo tronco móvel de Graham, não é a dor de Martha, mas a de todos, e em Frontier (1935) é a solidão e a esperança indomada de gerações de jovens mulheres que se revela. Assim, Gesicht der Nacht (1929) e outros solos de Wigman emanam a angústia da guerra e da morte comum à geração que viveu o primeiro conflito mundial e, frequentemente, a sublimação do eu em favor do compartilhamento é ressaltado por ela e tornado "absoluto" pelo uso da máscara ${ }^{23}$. Tanto Wigman como Graham, entretanto, com a intenção de criar ecos de suas próprias propostas temáticas e expressivas, coletivizando-as, sentiram logo a necessidade de circundar os próprios solos por um coro real, usado como amplificador ou antagonista.

Desse modo, o solo de dança oscila, nos anos da afirmação das grandes democracias e dos grandes totalitarismos, entre o fascínio da automultiplicação na coralidade, com o risco da pasteurização ideológica e do conformismo expressivo, e a resistência - muitas vezes intrinsecamente provocatória - numa autonomia expressiva que risca de se tornar isolamento político e pessoal e provocar sua expulsão como um corpo estranho. Nos vários contextos, serão determinantes os acontecimentos e as escolhas políticas que, geralmente, conseguirão quase extingui-lo ${ }^{24}$, até o renascimento pós-moderno nos anos sessenta-setenta.

\section{Solo/hoje}

Para concluir, o olhar pousa sobre o retorno preponderante do solo nas últimas décadas do século XX, sobre a "necessidade" poética e existencial para o dançarino-autor e sua suposta posição ideológica.

O solo de dança no século XX... Eugenia Casini Ropa

Março $2009-\mathrm{N}^{\circ} 12$ 


\section{Urdimento}

Na sociedade atual, que avança cada vez mais rapidamente em direção à globalização, dominada pela massificação dos gostos, das necessidades e dos comportamentos, bombardeada por uma espetacularidade difundida, superficial e envolvente, muitos dançarinos sentem a necessidade do isolamento, do silêncio, da suspensão do julgamento e da reflexão trabalhosa sobre os próprios meios e os próprios fins. Querem criar um face a face com o próprio material concreto básico, seu corpo-mente, que se libera do ruído midiático e da inquietude empresarial para viver a experiência artística psicofísica mais pobre e direta, e ao mesmo tempo, talvez, mais rica e total. No solo, pensamento e ação são uma coisa única. Como diz Laban, no trabalho profundo consigo mesmos buscamos, ainda e sempre, alcançar aquela área de "silêncio interior" na qual nasce a dança, aquele território em que o pensamento ganha vida através do movimento, sem a mediação da palavra ${ }^{25}$.

Esse renascimento do solo é composto, dos anos sessenta em diante até hoje, por vários fatores individuais ou compartilhados ${ }^{26}$, às vezes contraditórios entre si: por exemplo, a necessidade de reelaborar de modo próprio os materiais elaborados com outros coreógrafos em trabalhos de grupo ou de encontrar a própria estrada na dança, partindo de uma formação heterogênea, feita de breves contatos com professores, técnicas e poéticas diversas; ou, pelo contrário, a necessidade de elaborar sozinho novas formas e temáticas que serão depois levadas ao trabalho de grupo. Mas influenciam também a convicção democrática de não poder ou querer impor aos outros seus próprios movimentos; a maior rapidez, praticidade e, sobretudo, profundidade do trabalho solitário, sem ter que verbalizar, explicar e adaptar ideias e movimentos; a possibilidade de usar formas de improvisação sem limites criativos; a liberdade mentalmente excitante de criar parceiros imaginários (pessoas, coisas ou ambientes); o fascínio e o medo do desafio a si mesmo ao criar sozinho e se propor ao público, tentando ser compreendido; a exploração de aspectos psicológicos e autobiográficos, que permite no solo uma forma de auto-análise e de pesquisa da identidade pessoal; e assim por diante.

Do ponto de vista ideológico, tudo isso parece ainda constituir um comportamento contracorrente e de resistência. O solo em época de modas massificadas, a diversidade individual em época de assimilação em escala planetária, a criação artesanal em época de grandes cadeias de negócios, a profundidade introspectiva em época de exterioridade exibida, a fé na expressão corpórea orgânica e na relação individual presencial em época de exaltação do inorgânico e da comunicação virtual parecem querer constituir um bolsão de resistência, rebelde ao controle e à pasteurização.

Por outro lado, essas escolhas ético-poéticas normalmente pensadas e rigorosas ou, de todo modo, indomáveis ao conformismo e, às vezes, até

\footnotetext{
${ }^{25}$ Laban considera que a verdadeira arte do movimento fundase na capacidade que 0 artista tem de "pensarem-movimento" (contraposto a "pensar-empalavras"), ou seja, transformar diretamente os estímulos sinestésicos em impulsos cinestésicos (cf. LABAN, 1999, p. 21).

${ }^{26}$ É interessante, a este propósito, 0 artigo de Sally Banes, Going Solo, publicado em "Dance Ink", n. 3-4, no inverno de 199293 e, em seguida, reeditado por ela na coletânea BANES, 1994, pp. 348-352, que propõe os pontos de vista sobre 0 solo de dançarinos americanos pósmodernos.
} 


\section{Urdimento}

aparentemente ascéticas, também são frequentemente, e cada vez mais em alguns países, uma verdadeira estratégia de sobrevivência da dança e dos dançarinos, uma direção quase obrigatória em tempos de recessão econômica ou de falta de incentivo público à arte, eternamente pouco valorizada. Se as políticas culturais dão sempre menos espaço e apoio à pesquisa artística - e a dança artística está cada vez mais entre as primeiras penalizadas - dançar solos pode ser, de fato, o único modo prático de continuar o próprio trabalho e sobreviver materialmente. Um grupo exige tempos e espaços adequados, remuneração, organização, estrutura e tem exigências maiores e custos de circulação; o solo pode nascer em um salão, viajar num carro, ser apresentado em espaços pequenos e alternativos, independentemente da indústria do espetáculo. Dançar solos quer dizer também poder fugir das lógicas quantitativas das subvenções públicas e autogerir, além dos próprios instrumentos criativos, a própria vida profissional.

Assim sendo, entre necessidade expressiva e tática, em luta contínua pela existência da própria arte, na alvorada do século XXI o solo de dança continua a produzir, sem clamor, mas com insistência tenaz, através da presença incongruente e do contágio empático de seus corpos vivos e falantes no movimento, sua crítica silenciosa, direta ou indireta, à sociedade que o circunda e o gera.

\section{Referências bibliográficas}

BANES, Sally. Democracy Body: Judson Dance Theater 1962-64. Ann Arbor: UMI Research, 1983.

Terpsichore in Sneakers: Post-modern dance. Hanover: Wesleyan University, 1987.

Writing Dancing in the Age of Postmodernism. Hanover: Wesleyan Univ. Press, 1994.

Dancing Women: Female Bodies on Stage. Londres \& Nova Iorque: Routledge, 1998.

Baxmann, Inge. Mythos: Gemeinschaft. Körper- und Tanzkulturen in der Moderne. Munique: Wilhelm Fink Verlag, 2000.

BURT, Ramsay. Alien Bodies. Representation of modernity, 'race' and nation in early modern dance. Londres \& Nova Iorque: Routledge, 1998 .

CARANDINI, Silvia; VACARINO, Elisa (org.). La generazione danzante. L'arte del movimento in Europa nel primo Novecento. Roma: Di Giacomo, 1997.

CASINI ROPA, Eugenia. La danza e l'agitprop. I teatri-non-teatrali nella cultura tedesca del primo Novecento. Bolonha: il Mulino, 1988.

(org.). Alle origini della danza moderna. Bolonha: il Mulino, 1990. 


\section{Urdimento}

Mary Wigman. Danza di gruppo e danza corale. "Culture Teatrali", n.14, primavera 2006.

(org.). Béla Balász, Scritti di teatro. Florença-Milão: La casa Usher, 1980, pp. 105-106.

CHALFA RUYTER, Nancy Lee. Reformers and Visionaires. The Americanisation of the Art of Dance. Nova Iorque: Dance Horizons, 1979.

DALY, Ann. Done into Dance. Isadora Duncan in America. Bloomington \& Indianápolis: Indiana University Press, 1995.

DUNCAN, Isadora. The Art of the Dance. Nova Iorque: Theatre Arts Monthly, 1928.

Lettere della danza. Florença-Milão: La casa Usher, 1980.

FRANKO, Mark. Dancing Modernism/Performing Politics. Bloomington \& Indianápolis: Indiana Univ. Press, 1995.

Jaques-Dalcroze, Émile. Il ritmo, la musica e l'educazione. Turim: ERI, 1986.

KENDALL, Elisabeth. Where she danced. The Birth of American Art-Dance. Berkeley: California University Press, 1979.

LABAN, Rudolf. The Mastery of Movement on the Stage. Londres: Macdonald \& Evans, 1950

L'arte del movimento. Macerata: Ephemeria, 1999.

LISTA, Giovanni. Loïe Fuller. Danseuse de la Belle Époque. Paris: Stock-Édition d'Art Somogy, 1994.

MISLER, Nicoletta (org.). In Principio era il corpo... l'Arte del Movimento a Mosca negli anni Venti. Milão: Electa, 1999.

PETER, Frank-Manuel. Valeska Gert. Tänzerin, Schauspielerin, Kabarettistin. Berlin: Edition Heinrich, 1987.

SPERLING, Jody. Skirting the image. Proceedings XXII Meeting, Society of Dance History Scholars, 10-13 giugno 1999, Wisconsin: Stoughton, 2000.

VACCARINO, E. (org.). Giannina Censi. Danzare il Futurismo. Milão: MART, Electa, 1998.

WIGMAN, Mary. Die Sprache des Tanzes. Stuttgart: Battenberg, 1963. 